\title{
Anticipate, Target and Characterize: MS²-anticipated C-glycosylflavones from Erythrococca anomala
}

\section{(ㄷ)(1) $(9)$}

\section{Authors}

Tapé Kouamé1, 2, Timothée Okpekon², Nicaise F. Bony³ ${ }^{3}$ Solenn Ferron ${ }^{4}$, David Bonnaffé ${ }^{5}$, Jérôme Vanheuverzwijn 6 , Zhiyu Zhou' ${ }^{6}$, Véronique Fontaine ${ }^{6}$, Amon Diane N'Tamon ${ }^{1,3}$, Jean-François Gallard7, Karine Leblanc ${ }^{1}$, Jean-Christophe Jullian', Corto Miel', Pierre Champy', Mehdi A. Beniddir', Pierre Le Pogam¹

\section{Affiliations}

1 Équipe “Chimie des Substances Naturelles" Université Paris-Saclay, CNRS, BioCIS, Châtenay-Malabry, France

2 Laboratoire de Chimie Organique et de Substances Naturelles (LCOSN), UFR Sciences des Structures de la Matière et Technologie, Univ. FHB, Abidjan 22, Cote d'Ivoire

3 Département de Chimie Analytique, Minérale et Générale, Technologie Alimentaire, UFR Sciences Pharmaceutiques et Biologiques, Univ. FHB, Abidjan 06, Cote d'Ivoire

4 Université de Rennes, CNRS, ISCR (Institut des Sciences Chimiques de Rennes) - UMR 6226, Rennes, France

5 Université Paris-Saclay, CNRS, Institut de chimie moléculaire et des matériaux d'Orsay, Orsay, France

6 Unité de Microbiologie, Chimie Biorganique et Macromoléculaire, Université libre de Bruxelles (ULB), Bruxelles, Belgium

7 Institut de Chimie des Substances Naturelles, CNRS, ICSN UPR 2301, Université Paris-Saclay, Gif-sur-Yvette, France

Key words natural products anticipation, molecular networking, flavones, Erythrococca anomala, Euphorbiaceae.

received 02.06 .2021

revised 28.06.2021

accepted 19.07.2021

\section{Bibliography}

Planta Med Int Open 2021; 8: e131-e142

DOI 10.1055/a-1576-4351

ISSN 2509-9264

(c) 2021. The Author(s).

This is an open access article published by Thieme under the terms of the Creative Commons Attribution-NonDerivative-NonCommercial-License, permitting copying and reproduction so long as the original work is given appropriate credit. Contents may not be used for commercial purposes, or adapted, remixed, transformed or built upon. (https://creativecommons. org/licenses/by-ncnd/4.0/)

Georg Thieme Verlag, Rüdigerstraße 14,

70469 Stuttgart, Germany

\author{
Correspondence \\ Dr. Pierre Le Pogam \\ Équipe “Chimie des Substances Naturelles” Université \\ Paris-Saclay \\ CNRS, BioCIS \\ 5 rue J.-B. Clément \\ 92290 Châtenay-Malabry \\ France \\ Tel.: + 331468355 97, Fax: + 33146835399 \\ pierre.le-pogam-alluard@universite-paris-saclay.fr \\ Dr. Mehdi A. Beniddir \\ Équipe “Chimie des Substances Naturelles” Université \\ Paris-Saclay \\ CNRS, BioCIS \\ 5 rue J.-B. Clément \\ 92290 Châtenay-Malabry \\ France \\ Tel.: + 331468355 87, Fax: + 33146835399 \\ mehdi.beniddir@universite-paris-saclay.fr
}

\# Supplementary material is available under https:// doi.org/10.1055/a-1576-4351

\begin{abstract}
We herein report on the first chemical assessment of Erythrococca anomala (Juss. ex Poir.) Prain (Euphorbiaceae), a genus that was - to the best of our knowledge - not studied yet from a phytochemical perspective. A molecular networking strategy was implemented to rapidly identify the known specialized metabolites from untargeted MS/MS analyses of $E$. anomala leaves ethanolic extract. This strategy allowed for the identification of diverse $C$-glycosyl flavones and a cursory examination of MS/MS spectra could extend the GNPS-provided annotation to pinpoint the structural novelty of further derivatives. The isolation of the sought-after structures could be streamlined based on MS-guidance and their structures, determined through extensive NMR analyses, displayed structural features in line with MS²-based predictions. Anticipating sharp struc-
\end{abstract}


tural features at an early stage of the dereplication process through a critical assessment of the tandem mass spectrometric landmarks was essential to embark on the isolation of the newly reported structures owing to the elevated number of flavonoid glycosides isomers thereof formerly known, which would have deterred us from isolating them without the support of additional tandem mass spectrometric information. The isolation of the main components of the ethanolic extract completed the currently provided chemical report on $E$. anomala, also resulting in the description of a new phenylethanoid derivative (3) and of a new orcinol-based dimer (4). Anomaloflavone (1) exhibit significant activities with minimal inhibitory concentration values of $25 \mu \mathrm{g} / \mathrm{mL}$ against Staphylococcus aureus and Mycobacterium smegmatis while failing to exert an antibacterial activity against Pseudomonas aeruginosa, while being devoid of cytotoxicity against SiHa cells.

\section{Introduction}

The Euphorbiaceae plants represent one of the largest families of higher plants with more than 300 genera, 8000 species and about 50 tribes divided into seven subfamilies [1]. Fuelled by the diverse interests lying in euphorbs, decades of intensive phytochemical campaigns shed light on a wealth of specialized metabolites dominated by terpenoids, alkaloids, cyanogenic glycosides, tannins, and glucosinolated lipids holding more or less significant chemotaxonomic relevance. The different subfamilies of this family were unevenly studied from a phytochemical perspective and as such, no report could be found on the chemical constituents of species pertaining to the genus Erythrococca (Acalyphoideae - Acalyphae - Claoxylinae). The genus Erythrococca comprises 40 species, encountered from southern Africa to Ethiopia. Among these, Erythrococca anomala (Juss. ex. Poir.) Prain is a spiny dioecious shrub that can reach 3 meters tall and that widely occurs in West tropical Africa in savannah forest relics, riverine forests and coastal thickets [1]. Decoction of leaves represent a valued traditional remedy especially to expel tapeworms, while also being endowed with analgesic, antiseptic, and purgative properties [2]. For this first assessment of $E$. anomala specialized metabolite content, a molecular networking (MN) strategy was undertaken on the ethanolic extract of $E$. anomala leaves. This workflow resulted in dereplicating C-glycosylflavones and these assignments were individually reviewed through the manual inspection of MS/MS spectra for careful comparison against former literature reports having rationalized the fragmentation of these structures. The cursory examination of individual MS/MS data could also extend the annotations provided by the MN workflow to propose some further flavones, corresponding to either known or so far unknown structures. This in-depth curation of $\mathrm{MS}^{2}$ data guided the subsequent phytochemical investigation towards these tentatively novel structures, which were confirmed as anticipated following extensive NMR evidence. Advanced analytical strategies are increasingly necessary to pinpoint new natural products and avoid unnecessary re-isolation of known compounds, most often arising in much higher amounts. The molecular-networking strategy proved highly efficient to depict the chemical space covered by metabolomes in an attempt to focus on features holding important probabilities of being unknown [3]. The anticipation of unknown compounds is a further milestone in the 2021 quest for new natural products [4]. A significant achievement in the field relies on the MetWork platform to perform in silico derivatization of dereplicated compounds based on formerly implemented biochemical transformations and subsequent CFM-ID [5] simulation of their tandem mass spectrum for comparison with experimental $\mathrm{MS}^{2}$ spectra [6]. We recently extended this logic of in silico anticipation to organic chemistry reactions [7]. A thorough phytochemical investigation provided additional insights into the chemical composition of E. anomala, having resulted in the isolation of 5 known compounds together with a new phenylethanoid derivative and of a new orcinol-based dimer. The antimicrobial evaluation and cytotoxicity of the new flavonoid isolates are also being reported.

\section{Results and Discussion}

To get a first insight into $E$. anomala metabolites, the ethanolic extract of its leaves was profiled by HPLC/HRMS². These analytical fingerprints were then preprocessed following the feature-based molecular networking workflow [8]. The dereplication of the extract against the spectral libraries hosted by the GNPS [9] afforded a dozen of hits, spreading across different phytochemical classes, which were overall consistent with former reports related to Euphorbiaceae plants. At first, seven hits related to $C$-glycosylflavones, comprising entries with one or two sugar moieties, could be observed in the molecular network (See S1 Supplementary Material). The soundness of these hits and their consistency with tandem mass spectrometric data will be discussed in a dedicated section, but the detection of such widespread metabolites is not surprising in Euphorbiaceae which were already known for producing such phytochemicals [10]. The second structural series tentatively identified corresponded to a collection of peptide derivatives related to $\mathrm{N}$-benzoylphenylalanine and/or $\mathrm{N}$-benzoylphenylalaninol differing in their acetylation status and in their intermonomeric bonding. Although uncommon in plants and most often reported from fungal source, all the dereplicated compounds were already reported from Euphorbiaceae or Phyllanthaceae plants: $N$-benzoylphenylalaninol, aurantiamide, $O$-Acetyl- $N$ - $\left(N^{\prime}\right.$-benzoyl)phenylalanylphenylalaninol, asperphenamate, and asperglaucide. The last tentative assignment corresponded to bisresorcinol. Although euphorbiaceous plants are not known as alkylresorcinol producers, it is worth underlining that Wagner et al. reported on orcinol glycosides in Phyllanthus klotzschianus Müll.Arg. [11]. Notwithstanding the rather scarce taxonomic support to this last tentative tagging, the structures isolated during the subsequent phytochemical investigation provide, to a certain extent, some credit to this annotation.

Considerable efforts were drawn towards deciphering the mass spectrometric fragmentation of flavonoid glycosides and perhaps more saliently yet to C-glycosylflavones [12], which are not ame- 
nable to sugar hydrolysis and are thus more difficult to elucidate, especially prior to the wide scale deployment of 2D NMR sequences [13]. The differentiation between C-6 and C-8 monoglycosylated flavone isomers proved especially tricky, and was formerly based on the product ions specific ratio obtained following tandem mass spectrometry, in relation to differential hydrogen bonding instigated between the hydroxyl groups of flavonoid ring A and the hydroxyl groups of the sugar. In the current study, these MS/MS landmarks seem to be taken into account by the molecular networking processing since two isomeric nodes, distinguished thanks to MZmine 2 data preprocessing [14], were tagged as vitexin (C-8 glucosyl apigenin) and isovitexin (C-6 glucosyl apigenin) as depicted in the cluster in > Fig. 1. The MS/MS spectra recorded from these two precursors were examined to determine whether these assignments were supported by comparison with formerly reported tandem mass spectrometric data. At first, the different intensity ratios of the ${ }^{0,2} \mathrm{X}^{+} /{ }^{0,1} \mathrm{X}^{+}$signals in the low energy tandem mass spectrum (Collision Energy $=30 \mathrm{eV}$ ) of the $[\mathrm{M}+\mathrm{H}]^{+}$ion of the two molecules of this isomeric pair were strongly reminiscent of those reported by Waridel and co-workers [15], supporting the tentative assignment proposed by the molecular networking workflow. Likewise, the inspection of the MS² spectra of these protonated molecules obtained at higher collision energy $(C E=50 \mathrm{eV})$ highlighted formerly reported differences between $C-6$ and $C-8$ glycosylated flavones in the intensity ratio of the fragment ions at $\mathrm{m} / \mathrm{z} 283.06$ and 284.07 which again validated the GNPS-provided tagging [16].

The same cluster revealed two further nodes that were tentatively identified as swertisin (C-6 glucosyl 7-O-methylapigenin), hinting that a similar isomeric pair of $C-6$ and $C-8$ isomers comprising this $O$-methylated aglycone occurred in the plant. These two nodes instigated edges with both vitexin and isovitexin, but each of them displayed a higher cosine with a specific member of the vitexin/isovitexin pair. Gratifyingly, the node, at $\mathrm{m} / \mathrm{z} 447.1303$ ( $\triangleright$ Fig. 2) having the more elevated cosine score and the bigger number of shared peaks with the swertisin MS2 spectrum, comprised in the GNPS libraries, disclosed a higher similarity with isovitexin $(\mathrm{m} / \mathrm{z} 433.114$, cosine $\simeq 0.70)$ compared to vitexin $(\mathrm{m} / \mathrm{z}$ 433.114, cosine $\simeq 0.64$ ), supporting its likely $C-6$ glycosylated status. Conversely, the other swertisin-tagged node ( $\mathrm{m} / \mathrm{z} 447.1302$,) disclosed a higher degree of similarity with vitexin, hinting its plausible C-8 glycosylation and therefore rather identifying it as isoswertisin, a compound not uploaded to the GNPS repositories at the time of this study. The examination of the MS/MS spectra, related to this isomeric pair, validated this assumption which revealed the same diagnostic patterns of peaks, shifted by 14 atomic mass units. Within a Wessely-Moser isomeric pair, it is worth underlying that the $C-8$ glycosylated derivative was eluted before its $C-6$ analogue, in our chromatographic conditions, as found for vitexin and isovitexin.

The molecular network revealed a second flavone glycosidecontaining cluster that included nodes with higher molecular masses that were evocative of flavone derivatives with two sugar moieties. One of these nodes was tentatively identified as apigenin 6,8-digalactoside through the molecular-networking based dereplication process. During the phytochemical work-up of $E$. anomala, this compound could be isolated and high resolution mass spectrometry and NMR analyses identified this molecule as vicenin-II, an apigenin-6,8-di-C-hexoside derivative differing from the GNPS assignment $[17,18]$ by the nature of the sugar units. Further nodes could correspond to C-6,8-diglycosylated flavones with different sugar units at these two sites. In such cases, the type of sugar substituted at the $C-6$ and $C-8$ positions could be determined based on fragmentation differences in the product ion spectra of isomeric pairs in which the sugars are swapped, in a comparable way to what is observed with mono- $C$-glycosylflavones. Two such precursors pairs could be observed in the HPLC/DAD/MS2 run: a first one at $\mathrm{m} / \mathrm{z} 565.16$ and another at $\mathrm{m} / \mathrm{z} 579.17$ ( Fig. 3). Notwithstanding an important degree of overall similarity between the MS² spectra obtained from two isomeric precursors, some diagnostic signals could here as well lead to assign a tentative identity to these compounds.

Regarding the precursor ions at $m / z$ 565.16, the fragment ions at $m / z 451.11,457.11$ and 469.12 were reported to be diagnostic of schaftoside (i.e. 6-C- $\beta$-D-glucopyranosyl-8-C- $\alpha$-L-arabinopyranosylapigenin) as these were not observed throughout the fragmentation of isoschaftoside (i.e. 6-C- $\alpha$-L-arabinopyranosyl-8-C- $\beta$-D-glucopyranosylapigenin) [19]. These key signals were observed in the tandem mass spectrum of the isomer eluted at $20.5 \mathrm{~min}$ ( $>$ Fig. $\mathbf{3 b}$ ), while none of these appeared in the MS ${ }^{2}$ spectrum of the isomer detected at $19.0 \mathrm{~min}$ ( $>$ Fig. 3a), which supported the identification of the former as a 6-pentosyl-8-hexosyl apigenin, and of the latter as a 6-hexosyl-8-pentosyl apigenin derivative. A further MS/MS landmark of interest to discriminate there between is related to the trend of the $C-6$ sugar substituent to undergo a greater degree of fragmentation compared to the sugar residue located at $C-8$ $[20,21]$. For this purpose, when coping with di $C$-glycosylflavones comprising both a pentose and a hexose, the distinction of the isomers consists in comparing the relative abundance of the two different ${ }^{0,2} \mathrm{X}^{+}$signals arising at $m / z 445.11$ and $m / z 475.11$ in both MS/MS spectra. Following this approach, the comparatively higher ${ }^{0,2} X^{+}$signal refers to the sugar located at C-6. In our case, the $\mathrm{m} / \mathrm{z} 445$ to $\mathrm{m} / \mathrm{z} 475$ intensity ratio appeared higher in the spectrum of the compound eluting at $20.5 \mathrm{~min}$ ( $\triangleright$ Fig. 3b), which was evocative of a hexosyl residue at $C-6$ and therefore further supported a schaftoside-type substitution pattern, in line with our former assumptions.

The second isomeric pair appearing in this cluster was shifted by 14 atomic mass units compared to the first one ( $\mathrm{m} / \mathrm{z} 579.17)$, for a determined elemental composition of $\mathrm{C}_{27} \mathrm{H}_{30} \mathrm{O}_{14}$. Interestingly, these compounds displayed pronounced similarities in their MS2 spectra with a specific member of the former isomeric pair, consistently with their relative retention time, with the first eluted compound (retention time $=21.2 \mathrm{~min}$ ) resembling that of isoschaftoside while the second eluted molecule (retention time $=22.7 \mathrm{~min}$ ) disclosed more pronounced similarities with schaftoside spectral data. The aforementioned diagnostic signals were now shifted by 14 atomic mass units to be detected at $\mathrm{m} / \mathrm{z} 465.12,471.12$ and 483.13 in the $\mathrm{MS}^{2}$ spectrum of the compound eluted at $22.7 \mathrm{~min}$ ( $\triangleright$ Fig. 3d), in line with the ${ }^{0,2} X^{+}$signals now being detected at $\mathrm{m} / z$ 459.12 and $m / z 489.12$ in both MS/MS spectra, with compared intensity ratios similar to those outlined in the tandem mass spectrometric data of the first isomeric pair. These spectroscopic features hinted that these compounds should correspond to schaftoside and isoschaftoside derivatives having their apigenin component substituted by a methyl group. When searching this molecular formula in the Dictionary of Natural Products (DNP), 135 

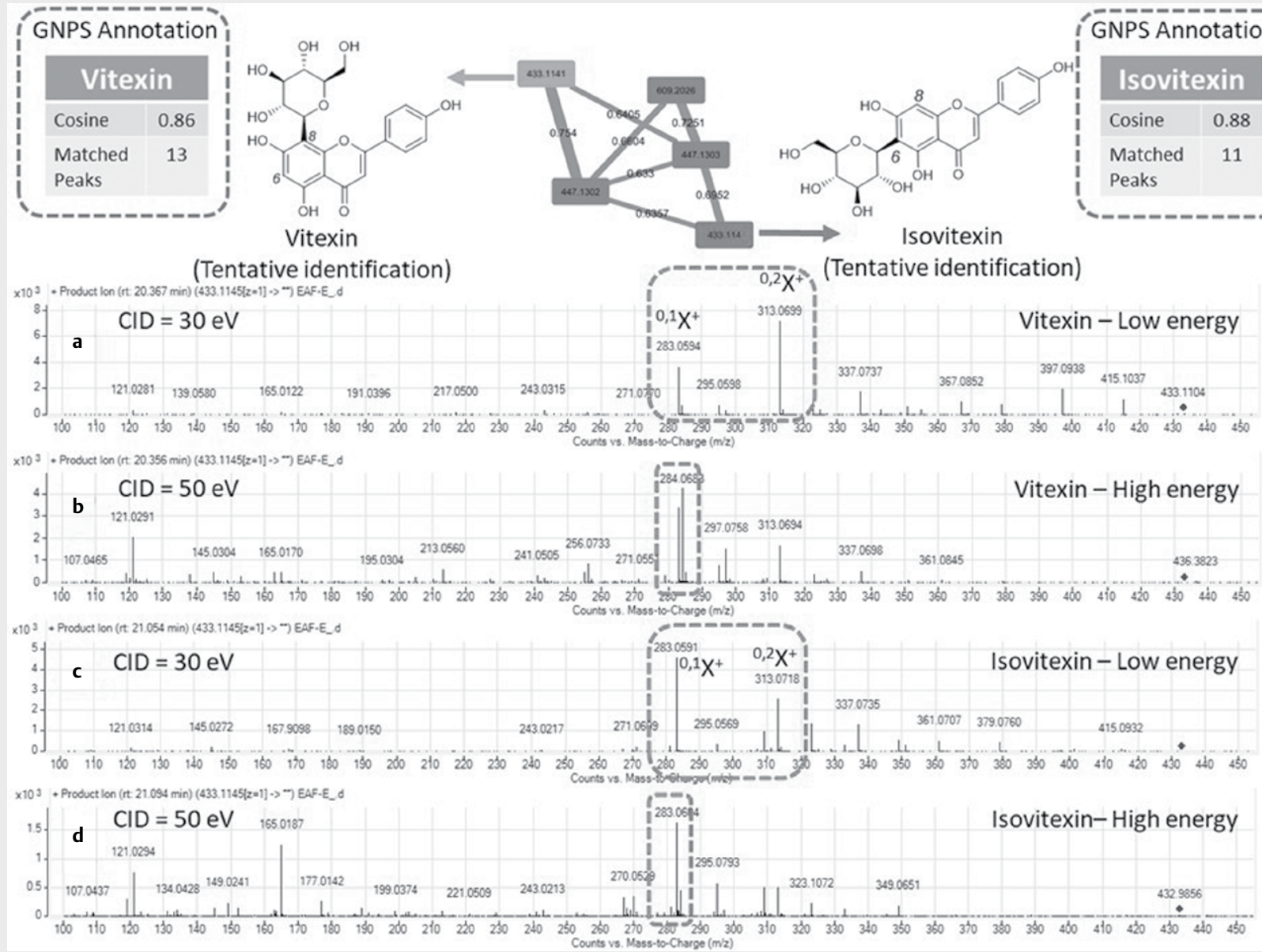

- Fig. 1 Cluster disclosing the nodes annotated as vitexin and isovitexin by the GNPS and analytical scores of their relative matches. a and b. Low and high-energy (CID = 30 and $50 \mathrm{eV}$, respectively) MS/MS spectra of the ion at $\mathrm{m} / \mathrm{z} 433.1145$ tentatively tagged as vitexin (retention time: 20.4 $\mathrm{min})$. $\mathbf{c}$ and $\mathbf{d}$. Low and high-energy MS/MS spectra of the ion at $\mathrm{m} / \mathrm{z} 433.1145$ tentatively tagged as isovitexin (retention time: $21.0 \mathrm{~min})$. The emphasized peaks refer to key signals as outlined in the discussion.

hits were found among which more than 100 entries corresponded to flavonoids! Manually refining these different flavonoids led to discard most of these propositions, so that only one compound displayed the structural elements outlined so far, viz. a 6,8-C-diglycosylflavone with a methylated apigenin core: 6-C-glucosyl-8-Carabinosylgenkwanin [22]. We therefore decided to focus the isomeric species deemed to correspond to the 6-pentosyl-8-hexosyl methylated flavone.

The last remaining node in this $\mathrm{C}$-glycosylflavone-containing cluster corresponded to a molecular formula of $\mathrm{C}_{27} \mathrm{H}_{28} \mathrm{O}_{16}(\mathrm{~m} / \mathrm{z}$ 609.1816). Compared to the other bidesmosic flavones described so far, the MS2 spectrum obtained from this ion showed a $\mathrm{Y}_{\mathrm{n}}{ }^{+}$ion at $\mathrm{m} / \mathrm{z} 447$ that hinted the existence of a $\mathrm{O}$-glycoside while also exhibiting a variety of fragment ions related to cross-ring cleavages of saccharidic residues, similar to those formerly observed in the tandem mass spectrum of swertisin/isoswertisin, evocative of a Cglycosidic residue. These spectroscopic features led us to surmise that this compound should be a $\mathrm{C}, \mathrm{O}$-diglycosylated flavone. The search of the generated molecular formula against the DNP database [23] revealed 10 different hits (accessed $14^{\text {th }}$ February 2021) among which nine were flavonoids. Yet, the flavonoids matching the elemental composition query either corresponded to $O$-diglycosylated flavones or to 3-methylglutaroylated $O$-glycosylflavones, which seemed to be inconsistent with the putative structural elements deduced from the cursory examination of the MS² data. Inferring that this compound had important chances to be unknown, we decided to target it for isolation and full structure elucidation.

The MS 2 landmarks outlined earlier made us gear our isolation efforts towards some specific compounds prioritized due to their presumed structural novelty. Accordingly, the isolation of the prioritized compounds, detected at $\mathrm{m} / \mathrm{z} 609.1816$ and at 579.1713, could be successfully performed using a suite of chromatographic separations. Due to this study being the first undertaken on E. anomala, we wished to complete this targeted pipeline with a more traditional, untargeted, phytochemical workflow. The isolation of the main constituents of the ethanolic extract shed light on structural classes not formerly identified in the molecular network. The structures of these compounds could be deduced from their spectroscopic data, including 1D and 2D NMR experiments and comparison with reported data as syringaresinol [24], lariciresinol 


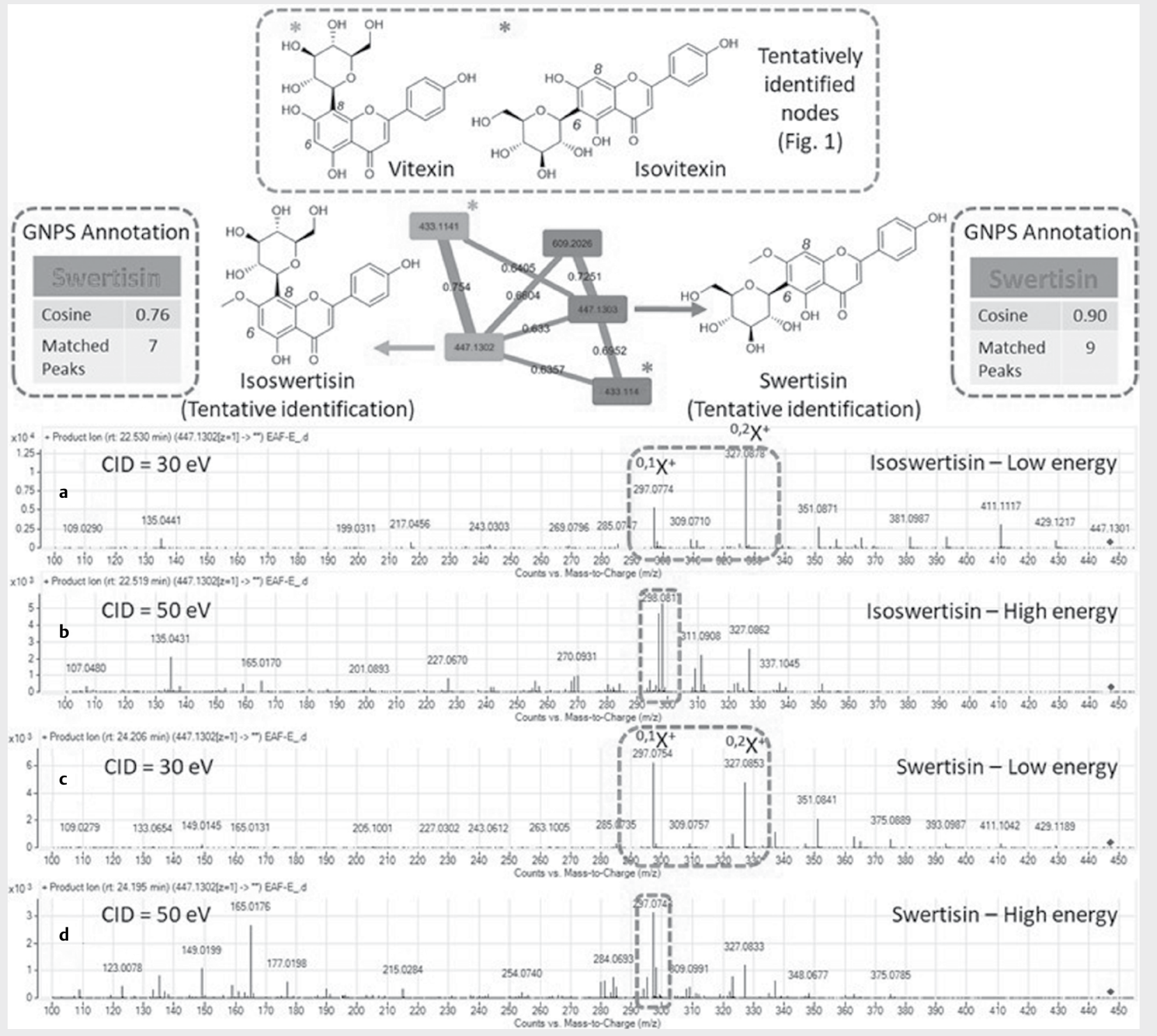

- Fig. 2 Cluster disclosing the two nodes annotated as swertisin by the GNPS and analytical scores of their relative matches. a and $\mathbf{b}$. Low and highenergy MS/MS spectra (CID = 30 and $50 \mathrm{eV}$, respectively) of the first ion at $\mathrm{m} / \mathrm{z} 447.1302$ tentatively tagged as swertisin, but rather identified as isoswertisin based on manual inspection (retention time: $22.5 \mathrm{~min}$ ). $\mathbf{c}$ and $\mathbf{d}$. Low and high-energy MS/MS spectra (CID $=30 \mathrm{and} 50 \mathrm{eV}$, respectively) of the second ion at $\mathrm{m} / \mathrm{z} 447.1302$ tentatively tagged as swertisin (retention time: $24.0 \mathrm{~min}$ ). The emphasized peaks refer to key signals as outlined in the discussion.

[25], tanarifuranonol [26], vitexin [27], trematin [28], isocytisoside [29], and orcinol. The first three compounds were all known from Euphorbiaceae plants $[26,30]$ while orcinol seems to be a first report in this plant family. Gratifyingly, this traditional phytochemical pipeline also resulted in the isolation of two new compounds which both revealed an orcinol-type substitution pattern, anomaline (3) and diorcinol (4) ( $>$ Fig. 4).

Anomaloflavone (1) was isolated as an optically active amorphous solid with a molecular formula of $\mathrm{C}_{28} \mathrm{H}_{32} \mathrm{O}_{15}\left(\mathrm{~m} / \mathrm{z} 609.1816[\mathrm{M}+\mathrm{H}]^{+}\right.$, calcd. for $\left.\mathrm{C}_{28} \mathrm{H}_{33} \mathrm{O}_{15}, 609.1814\right)$, as deduced from HRESIMS measurements. Consistent with the tandem mass spectrometric observations which hinted a $\mathrm{C}, \mathrm{O}$-diglycosylated flavone, the ${ }^{1} \mathrm{H}$ and ${ }^{13} \mathrm{C}$ NMR data
( $\triangleright$ Table 1) indicated a C-6 (or C-8)- substituted flavone comprising two anomeric sites resonating at $\left(\delta_{\mathrm{H}} 4.68 / \delta_{\mathrm{C}} 72.5\right)$ and at $\left(\delta_{\mathrm{H}} 4.36 / \delta_{\mathrm{C}}\right.$ $104.1)$ that were respectively diagnostic of their $C$-glycosylated and $O$-glycosylated status, respectively $[13,31]$. The other sugar signals appeared overlapped between $\delta_{H} 3.07$ and 3.71. The ${ }^{1} \mathrm{H}$ NMR spectra revealed an olefinic signal at $\delta_{\mathrm{H}} 6.87 / \delta_{\mathrm{C}} 103.5$ which was typical of a $\mathrm{H}-3$ flavone signal, an aromatic signal at $\delta_{\mathrm{H}} 6.55 / \delta_{\mathrm{C}} 93.6$ that confirmed the pentasubstituted status of ring $A$, two doublets at $\delta_{H} 8.04$ and 7.11 (each $2 \mathrm{H}, \mathrm{d}, J=9.0 \mathrm{~Hz}$ ), typical of a $\mathrm{A}_{2} \mathrm{~B}_{2}$ spin system of ring $B$ of 4 '-substituted flavones and a methoxy group at $\delta_{\mathrm{H}} 3.86(3 \mathrm{H}, \mathrm{s})$. The location of the methoxy group was established based on the correlations from the protons resonating at $\delta_{H^{\prime}} 3.86$ and $C-4^{\prime}\left(\delta_{C} 163.3\right)$ and 


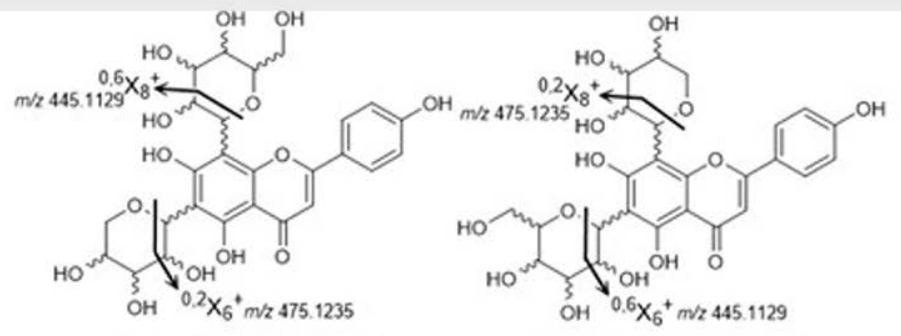

6-pentosyl-8-hexosyl-apigenin

6-hexosyl-8-pentosyl-apigenin
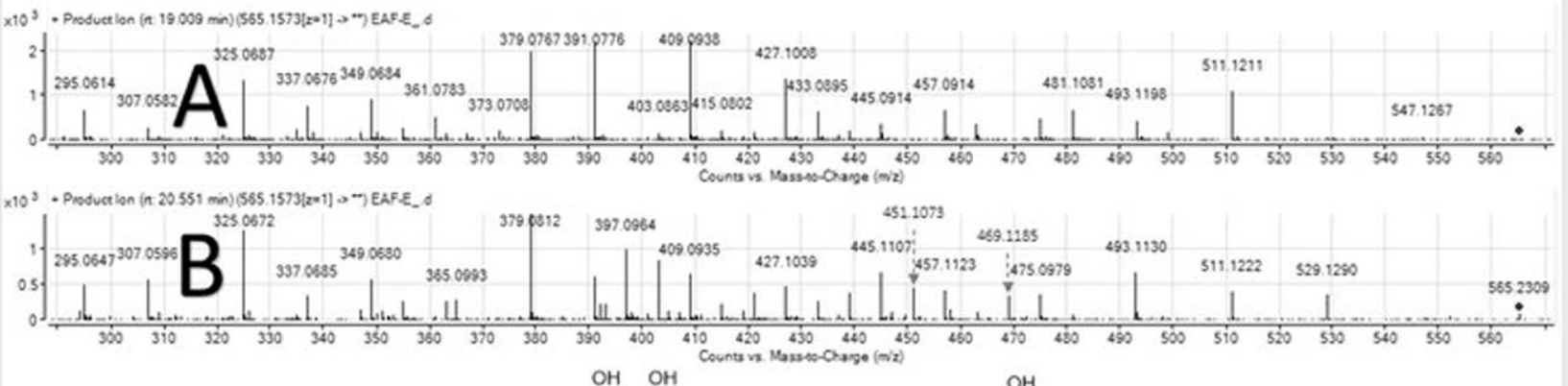

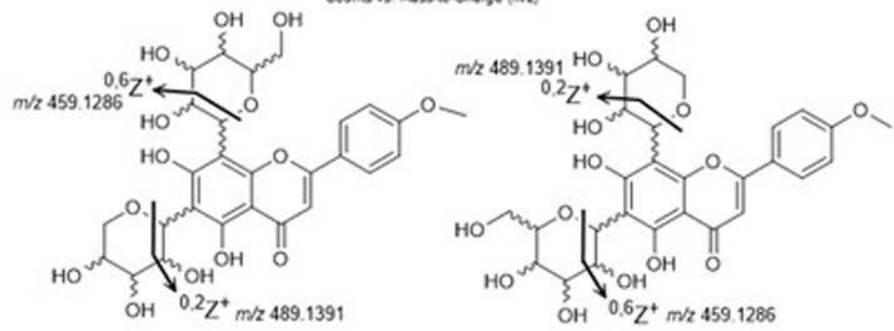

4'-O-Me-6-pentosyl-8-hexosyl-apigenin 4'-O-Me-6-hexosyl-8-pentosyl-apigenin
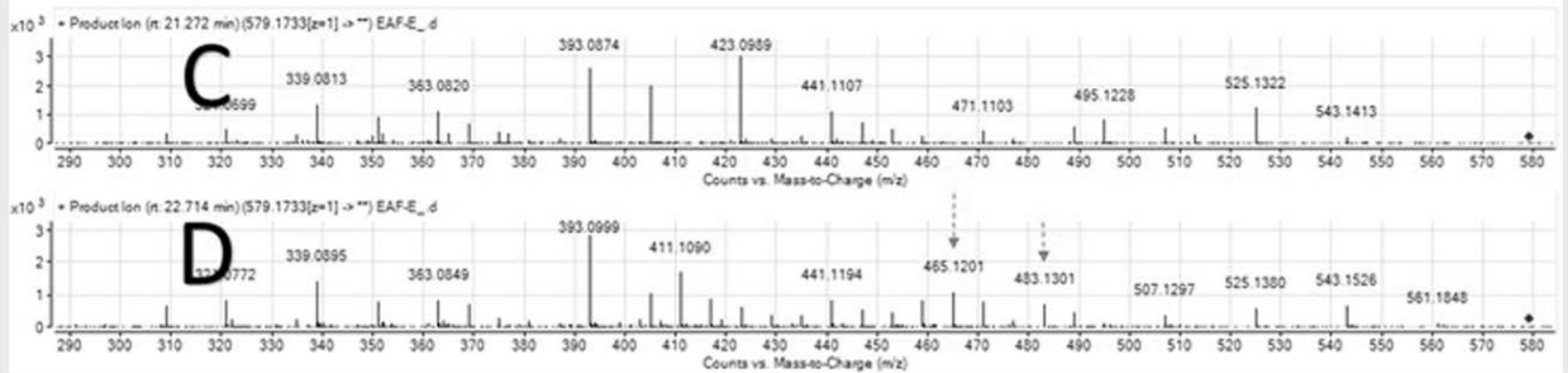

- Fig. 3 Low-energy MS/MS spectra $(C E=30 \mathrm{eV})$ of the ions at $\mathrm{m} / \mathrm{z} 565.16$ tentatively identified as a 6-C-pentosyl-8-C- hexosyl-apigenin (retention time: $19.0 \mathrm{~min}$ ) (a) and a 6-C-hexosyl-8-C-pentosyl-apigenin (retention time: $20.5 \mathrm{~min}$ ) (b) and possible candidates for the signals at $\mathrm{m} / \mathrm{z} 579.17$ (c) (retention time: $21.2 \mathrm{~min}$ ) and (d) (retention time: $22.7 \mathrm{~min}$ ). Note that the methylation site of the flavone component is depicted arbitrarily.

from the aromatic protons at $\delta_{\mathrm{H}} 7.11\left(\mathrm{H}-3^{\prime} / \mathrm{H}-5^{\prime}\right)$ and at $\delta_{\mathrm{C}} 8.04$ $\left(\mathrm{H}-2^{\prime} / \mathrm{H}-6^{\prime}\right)$ to $\mathrm{C}-4^{\prime}$. Altogether, these data determined the aglycone component of anomaloflavone as acacetin [32]. The ${ }^{13} \mathrm{C}$ NMR spectrum revealed 12 sugar signals ascribable to two hexose units. The cautious analysis of the ${ }^{13} \mathrm{C}$ NMR chemical shifts of $C-6\left(\delta_{C} 108.4\right)$ and $C-8\left(\delta_{C} 93.6\right)$ were reminiscent of those of $C-6$ glycosylated apigenin/ acacetin derivatives such as isovitexin [31], paraquinins A-C [33], or C-6 glycosylated flavones from Anthurium versicolor [34] whereas C-8 glycosylated flavones display ${ }^{13} \mathrm{C}$ chemical shift values around $\delta_{C} 99.0$ and $\delta_{C} 105.0$ for $C-6$ and $C-8$, respectively $[34,35]$. The HMBC correlations observed between both the anomeric proton detected at $\delta_{\mathrm{H}}$ $4.68\left(\mathrm{H}-1^{\prime}\right)$ and the hydrogen-bonded hydroxyl group at $\delta_{\mathrm{H}} 13.59(\mathrm{OH}-$
5) to $C-5$ and C- 6 confirmed that the disaccharide was bonded by a $C$ glycosidic linkage at C-6 ( $\mathbf{F i g}$. 5). The proton sequence of the inner sugar could be deduced from the COSY spectrum from $\mathrm{H}-1^{\prime}$ to $\mathrm{H}-6^{\prime}$ but the multiplicities and coupling constants could not be clearly readable in the spectra recorded in DMSO- $\mathrm{d}_{6}$ (S4, Supplementary Material). A second hexosyl unit could also be determined and the lack of any ${ }^{13} \mathrm{C}$ NMR glycosidation shift confirmed it being the terminal unit. The ${ }^{13} \mathrm{C}$ NMR data revealed a glycosidation shift at $C-3^{\prime}\left(\delta_{C} 90.5\right)$ that established the (1->3) linkage between the glycosyl units. A HMBC correlation from the anomeric proton at $\delta_{\mathrm{H}} 4.36\left(\mathrm{H}-1^{\prime}\right)$ to $\mathrm{C}-3^{\prime}\left(\delta_{\mathrm{C}} 90.5\right)$ confirmed this interglycosidic linkage. To determine the coupling constants related to the sugar components of anomaloflavone, new NMR 
spectra were acquired in $\mathrm{CD}_{3} \mathrm{OD}$ (S9-S14, Supplementary Material). The large coupling constants of the anomeric protons $\left(\mathrm{J}_{\mathrm{H}}\right.$ $1^{\prime}-\mathrm{H}-2^{\prime}=10.0 \mathrm{~Hz}$ and $\int_{\mathrm{H}-1^{\prime}-\mathrm{H}-2^{\prime}}=7.9 \mathrm{~Hz}$ ) determined the $\beta$-configuration of both sugar moieties. Subsequently, the axial orientation of the remaining sugar protons $\mathrm{H}-2^{\prime}$ to $\mathrm{H}-5$ ' and $\mathrm{H}-2^{\prime}$ to $\mathrm{H}-5^{\prime}$ could be deduced from the large magnitude of their coupling constant values, as collated in $>$ Table 1. These data confirmed the carbohydrate part of anomaloflavone as laminaribiose, in excellent agreement with the NMR data formerly reported by Hamburger and co-workers in both $\mathrm{CD}_{3} \mathrm{OD}$ and DMSO- $d_{6}$ on closely related $C$-glycosylflavones [36]. Accordingly, anomaloflavone was determined as acacetin 6-C-[ $\beta$-Dglucopyranosyl-(1->3)- $\beta$-D-glucopyranoside].

Anomalovicenin (2) was isolated as the sought-after feature with a precursor mass at $\mathrm{m} / \mathrm{z} 579.1713$, confirming its molecular formula to be $\mathrm{C}_{27} \mathrm{H}_{30} \mathrm{O}_{14}$ (calcd. for $\mathrm{C}_{27} \mathrm{H}_{31} \mathrm{O}_{14}, 579.17083$ ) presumably corresponding to a 6-C-pentosyl-8-C-hexosyl based on its fragmentation pattern. Consistent with the MS2 based-hypothesis developed earlier, the ${ }^{1} \mathrm{H}$ NMR spectrum of 2 recorded in DMSO- $d_{6}$ (S17, Supplementary Material) indicated that this compound was a C-6,8-diglycosylated flavone at the first glance. The spectroscopic data indeed indicated the presence of five different aromatic protons, four of which pertained to an $\mathrm{A}_{2} \mathrm{~B}_{2}$ spin system, with $\mathrm{H}-2^{\prime}$ and $\mathrm{H}-6^{\prime}$ 'sorting out as two doublets detected at $\delta_{\mathrm{H}} 8.15$ and 8.07 (accounting for $2 \mathrm{H}$ overall, each d, $J=8.4 \mathrm{~Hz}$ ), and $\mathrm{H}-3^{\prime} / \mathrm{H}-5^{\prime}$ also being detected as two doublets at $\delta_{\mathrm{H}}$ 7.13 and 7.08 ( $2 \mathrm{H}$ overall, $\mathrm{d}, J=8.4 \mathrm{~Hz}$ ) while the flavone signal $\mathrm{H}-3$ still resonated as a broad singlet at $\delta_{\mathrm{H}} 6.88(1 \mathrm{H}$, br s). Likewise, a cursory examination of the ${ }^{13} \mathrm{C}$ NMR data revealed a more or less obvious twinning of most A-ring signals and of sugar-related signals, with the occurrence of four different anomeric protons, inconsistent with the elemental composition of 2 . The ${ }^{13} \mathrm{C}$ NMR assignments deduced from the HSQC spectrum for the anomeric carbons resonated around $\delta_{C} 75$ ppm confirmed their MS2-awaited C-glycosylated status. The HMBC cross-peak of the protons at $\delta_{\mathrm{H}} 3.86$ to the carbon resonating at $\delta_{\mathrm{C}}$ 163.2 located a methoxy group at $\mathrm{C}-4^{\prime}$, in line with the predicted methylated status of the aglycone part of this compound. Exchangebroadened signals at ambient temperature are often observed for $C$ glycosylflavones [37,38]. This phenomenon is related to the coexistence of two rotamers about the bond tethering C -6 to the anomeric carbon of its C-linked sugar, especially in 6-C-glycosylated flavones displaying bulky substituents at C-7 or C-8 [39]. In this context, NMR acquisitions at higher temperatures can be conducted to improve spectral resolution and simplify NMR signal patterns, guiding us to attempt Variable Temperature (VT-NMR) experiments (S16, Supplementary Material). NMR spectra acquired at $373 \mathrm{~K}$ displayed sharp signals that allowed for the complete assignment of the ${ }^{1} \mathrm{H}$ and ${ }^{13} \mathrm{C}$ NMR data related to the sugar residues. COSY and HSQC sequences, in particular, determined a xylopyranose and a glycopyranose residue, based on their diagnostic chemical shifts and on the elevated magnitude of their readable coupling constants ( $\triangleright$ Table 2 ). Attachment sites of the two sugars could be determined owing to the long-range heteronuclear correlations outlined in $\triangleright$ Fig. 6. These HMBC correlations confirmed the linkage of the xylose residue to $C-6$, consistent with tandem mass spectrometric data which hinted the occurrence of a pentosyl residue at this specific position. The NOESY crosspeaks observed between the protons of the glycosyl residue and the aromatic proton $\mathrm{H}-\mathrm{2}^{\prime} / \mathrm{H}-\mathrm{6}^{\prime}$ validated the $\mathrm{C}-8$ location of this residue. Altogether, these spectroscopic data supported the elucidation of $\mathbf{2}$, namely anomalovicenin, as dis- closed in > Fig. 4. The $D$ absolute configuration of $\beta$-Glc and $\beta$-Xyl were assumed as those naturally occurring in $C$-glycosylflavones.

The detailed structure elucidation of the new compounds 3 and 4 is provided in the Supplementary Material (S23 and S30).

Some antiseptic claims in the ethnopharmacological use of E. anomala[2], along with the documented antibacterial activity of some flavones [40,41], guided us to evaluate the antibacterial activities of anomaloflavone (1) and anomalovicenin (2) on different bacteria. Anomalovicenin (2) was inactive on all tested bacteria. Anomaloflavone (1) showed a significant antibacterial activity against the Gram-positive S. aureus and on Mycobacterium smegmatis, with a $25 \mu \mathrm{g} / \mathrm{mL}$ MIC on both bacteria. However, it was inactive on the Gramnegative Pseudomonas aeruginosa. Owing to anomaloflavone being bactericidal against $S$. aureus (MBC $=\mathrm{MIC}$ ), it is tempting to infer that anomaloflavone (1) failed to be active against $P$. aeruginosa due to its hydrophobic outer membrane. Nevertheless, as anomaloflavone inhibits the growth of $M$. smegmatis too, notwithstanding its waxy cell wall composed of mycolic acids, it cannot be ruled out that specific target(s) could also be missing in P. aeruginosa. Interestingly, it is worth noting that anomaloflavone $(1)$ revealed no cytotoxicity $\left(I_{50}>100 \mu \mathrm{g} /\right.$ $\mathrm{mL}$ ) towards the human $\mathrm{SiHa}$ cell line. The positive controls used were vancomycin (MIC value of $1 \mu \mathrm{g} / \mathrm{mL}$ against $S$. aureus), cetrimide (MIC value of $0.1 \mu \mathrm{g} / \mathrm{mL}$ against $P$. aeruginosa), rifampicine (MIC value of $0.1 \mu \mathrm{g} / \mathrm{mL}$ against $M$. smegmatis), and orlistat (IC50 $=75 \mu \mathrm{g} / \mathrm{mL}$ in SiHa cell line).

The anticipation performed in this paper, is based on a MN strategy that clustered C-glycosylated flavones as two distinct families, annotated as such thanks to a few hits against the GNPS spectral libraries. Yet, annotation propagation carried out here did not rely on computer-based derivatizations. Instead, the cursory curation of the MS ${ }^{2}$ spectra related to non-dereplicated nodes allowed us to extend the GNPS-provided annotations based on the observation of diagnostic tandem mass spectrometric features extrapolated from signal patterns of dereplicated nodes.

The C-glycosylflavone emphasis of the current work seems ideally suited for this approach as these structures, very difficult to elucidate based on NMR studies, had their fragmentation pathways thoroughly discussed, especially through the salient contributions of Magda Claeys group [12]. However, the benefits retrieved from the early MS2-based recognition of structural details related to 1 and $\mathbf{2}$ lie way beyond a mere facilitation of their subsequent structure elucidation. A significant feature rendering the early curation of MS2 data of peculiar interest is that the newly reported structures have a common elemental composition, owing to the highly isomeric nature of flavonoids ( 9 flavonoids displaying the same formula than 1 and more than 100 for 2 ) so that their sole elemental composition would have deterred us from isolating them. The early in-depth curation of their MS2 data allowed us to refine these different hits to ascertain their structural novelty and thus exerted a crucial influence on the conducted phytochemical investigation.

The accuracy of the MS²-based predictions is worth being underlined as anomaloflavone turned out to be a C,O-diglycosylated flavone, as foreseen. The extent of information retrieved from anomalovicenin prior to its isolation is perhaps more impressive yet, as the correct location sites of the pentosyl and hexosyl residues could have been predicted. An inherent limitation of this strategy is the difficulty to predict the nature of the sugar components 


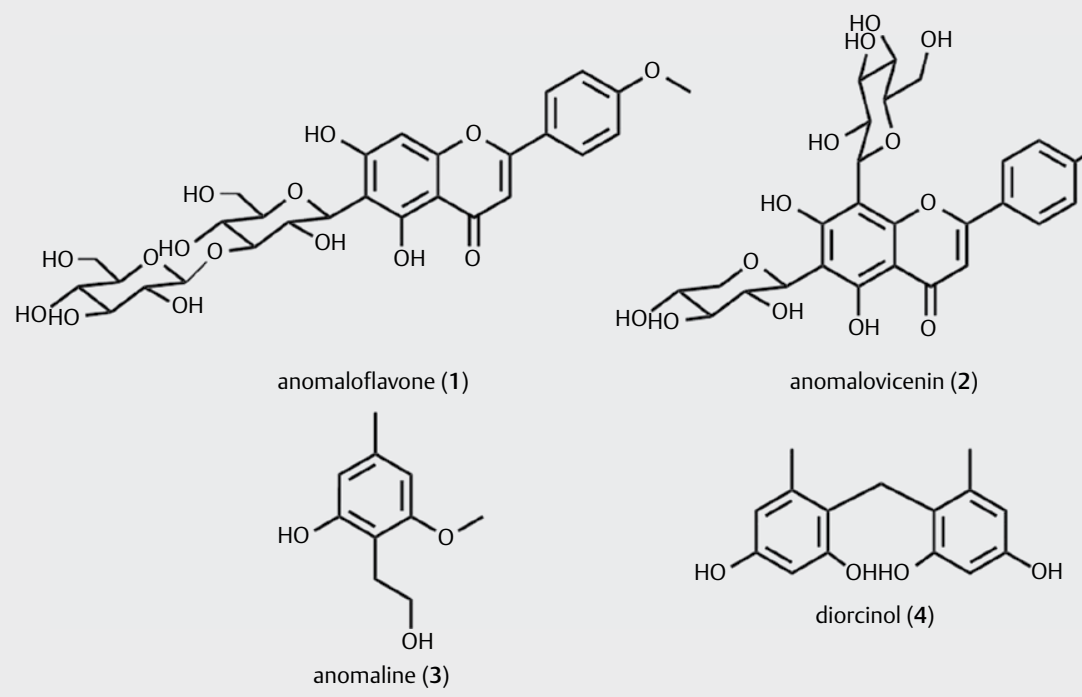

Fig. 4 Structures of new compounds isolated in the present work.

which is, generally speaking, a vexing problem in mass spectrometry [42]. From a naturalistic standpoint, we herein propose the first chemical report on a Erythrococca plant species, that also led to describe two new phenolic structures.

Interestingly, anomaloflavone (1) revealed a significant antibacterial activity against $S$. aureus and $M$. smegmatis while failing to exert a cytotoxic activity against SiHa cell line.

\section{Materials and Methods}

\section{General experimental procedures}

The NMR spectra were recorded on a Bruker AM-400 (400 MHz), and on a Bruker Avance III $500 \mathrm{MHz}$ spectrometer (Bruker, Bremen, Germany). NMR spectrometers were calibrated using solvent residual signals as references. Analytical HPLC runs were carried out using an Agilent LC-MS system comprising an Agilent 1260 Infinity HPLC hyphenated with an Agilent 6530 ESI-Q-TOF-MS operating in positive polarity. Open-column chromatography separations were performed on silica gel (40-63 $\mu \mathrm{m}$, Kieselgel, Merck) at atmospheric pressure or with Sephadex LH-20 (25-100 $\mu \mathrm{m}$, Pharmacia Fine Chemicals, USA). Sunfire preparative $C_{18}$ columns $(150 \times 30 \mathrm{~mm}$, i. d. $5 \mu \mathrm{M}$, Waters) were used for HPLC separations using a Waters Delta Prep (Waters Co., Milford, MA, USA) consisting of a binary pump (Waters 2525) and a UV-visible diode array detector (190$600 \mathrm{~nm}$, Waters 2996). TLC analyses were carried out on precoated silica gel $60 \mathrm{~F}_{254}$ (Merck) and spots were visualized by spraying with $1 \%$ sulfuric vanillin.

\section{Plant Material}

Erythrococca anomala (Juss. ex. Poir.) Prain whole plants were collected in Anepe area, Adzope, Ivory Coast (GPS E: 405353.98, N: $675123.91)$ in May 2017. The botanical identification was performed at the Centre National de Floristique (CNF) - Université Félix
Houphouët Boigny - Abidjan (Côte d'Ivoire). A voucher specimen (No. OAT-EA-2018) has been deposited at the herbarium of CNF.

\section{Chromatographic and mass spectrometric analysis}

Samples were analyzed using an Agilent 6530 Accurate Mass Q-TOF coupled with a 1260 Agilent Infinity LC system fitted with a Sunfire $C_{18}$ column $(150 \mathrm{~mm} \times 2.1 \mathrm{~mm}$; i. d. $3.5 \mu \mathrm{m}$, Waters, Milford, MA, USA) with a flow rate at $0.25 \mathrm{~mL} / \mathrm{min}$. Full scan mass spectra were acquired in the positive polarity in a m/z 100 to 1200 mass range. Capillary temperature, source voltage and sheath gas flow rate were set at $320{ }^{\circ} \mathrm{C}, 3.5 \mathrm{kV}$, and $10 \mathrm{~L} / \mathrm{min}$, respectively. Capillary, fragmentor, and skimmer voltages were set at $3500 \mathrm{~V}, 175 \mathrm{~V}$ and $65 \mathrm{~V}$, respectively. Four scan events were used: positive MS, mass range encompassing m/z 100-1200, and three data-dependent MS/MS scans of the five most intense ions from the first scan event. Three collision energies (i.e. 30, 50, and $70 \mathrm{eV}$ ) were used for MS/ MS data generation. Purine $\left(\mathrm{C}_{5} \mathrm{H}_{4} \mathrm{~N}_{4}, \mathrm{~m} / z\right.$ 121.050873) and HP0921 (hexakis ( $1 \mathrm{H}, 1 \mathrm{H}, 3 \mathrm{H}$-tetrafluoropropoxy)-phosphazene $\mathrm{C}_{18} \mathrm{H}_{18} \mathrm{~F}_{24} \mathrm{~N}_{3} \mathrm{O}_{6} \mathrm{P}_{3}, \mathrm{~m} / z$ 922.009798) were used as internal lock masses. Full scans were acquired at a resolution of 10.000 ( $\mathrm{m} / \mathrm{z} 922)$ and 4.000 ( $\mathrm{m} / \mathrm{z} 121)$. A permanent MS/MS exclusion list criterion was established to prevent oversampling of the internal calibrant.

\section{MZmine data processing and Molecular Networking Parameters}

The MS/MS data files were converted from the .d in-house Agilent data format to .mzXML using the MS Convert software, as included in the ProteoWizard package [43]. The .mzXML files were then processed using the MZmine 2 v.52 workflow. The mass detection was performed using a threshold of 1.0E4. The ADAP chromatogram builder was obtained using a minimum group scan size of 4 , a group intensity threshold of $1.0 \mathrm{E} 4$, a minimum highest intensity of $1.0 \mathrm{E} 5$ and $\mathrm{m} / \mathrm{z}$ tolerance of $0.05 \mathrm{Da}$ or $5 \mathrm{ppm}$ [44]. The ADAP wavelets deconvolution algorithm was performed using the following settings: $\mathrm{S} / \mathrm{N}$ threshold $=10$, minimum feature height $=3$, coefficient/area threshold $=3$, peak duration 
- Table $1{ }^{1} \mathrm{H}$ and ${ }^{13} \mathrm{C}$ NMR Data for Anomaloflavone (1) (500/125 MHz, at 298 K)

\begin{tabular}{|c|c|c|c|c|}
\hline \multirow[b]{2}{*}{ no. } & \multicolumn{2}{|c|}{ Anomaloflavone $^{a}$} & \multicolumn{2}{|c|}{ Anomaloflavone $^{b}$} \\
\hline & $\begin{array}{l}\delta_{\mathrm{H}}, \text { mult. } \\
(U \text { in } \mathrm{Hz})\end{array}$ & $\delta_{\mathrm{C}}$, type & $\begin{array}{l}\delta_{\mathrm{H}}, \text { mult. } \\
(U \text { in } \mathrm{Hz})\end{array}$ & $\delta_{\mathrm{C}}$, type \\
\hline 2 & & 163.1, C & & $166.0, C$ \\
\hline 3 & $6.87, \mathrm{~s}$ & $103.5, \mathrm{CH}$ & $6.65, \mathrm{~s}$ & $104.5, \mathrm{CH}$ \\
\hline 4 & & 182.0, C & & $184,2, C$ \\
\hline 5 & & $160.8, \mathrm{C}$ & & 162.3, C \\
\hline 6 & & 108.4, C & & 109.1, C \\
\hline 7 & & 163.4, C & & 165.1, C \\
\hline 8 & $6.55, \mathrm{~s}$ & 93.6, $\mathrm{CH}$ & $6.52, \mathrm{~s}$ & 95.3, $\mathrm{CH}$ \\
\hline 9 & & 153.6, C & & 158.9, C \\
\hline 10 & & 103.4, C & & 105.2, C \\
\hline $1^{\prime}$ & & 122.7, C & & $124.5, C$ \\
\hline $2^{\prime}$ & $\begin{array}{l}8.04, d \\
(7.5)\end{array}$ & $128.3, \mathrm{CH}$ & $\begin{array}{l}7.94, d \\
(8.4)\end{array}$ & $129.2, \mathrm{CH}$ \\
\hline $3^{\prime}$ & $\begin{array}{l}7.11, d \\
(7.5)\end{array}$ & 114.6, CH & $\begin{array}{l}7.09, \mathrm{~d} \\
(8.4)\end{array}$ & 115.6, CH \\
\hline $4^{\prime}$ & & 162.3, C & & 164.5, C \\
\hline $5^{\prime}$ & $\begin{array}{l}7.11, d \\
(7.5)\end{array}$ & 114.6, CH & $\begin{array}{l}7.09, d \\
(8.4)\end{array}$ & 115.6, CH \\
\hline $6^{\prime}$ & $\begin{array}{l}8.04, d \\
(7.5)\end{array}$ & $128.3, \mathrm{CH}$ & $\begin{array}{l}7.94, d \\
(8.4)\end{array}$ & $129.2, \mathrm{CH}$ \\
\hline $1^{\prime \prime}$ & $\begin{array}{l}4.68, d \\
(8.0)\end{array}$ & $72.5, \mathrm{CH}$ & $\begin{array}{l}4.94, \mathrm{~d} \\
(10.0)\end{array}$ & 74.9, $\mathrm{CH}$ \\
\hline $2^{\prime \prime}$ & $\begin{array}{l}4.32, \mathrm{dd} \\
(8.0)\end{array}$ & 68.6, $\mathrm{CH}$ & $\begin{array}{l}4.42, \mathrm{dd} \\
(10.0,9.5)\end{array}$ & 71.6, CH \\
\hline $3^{\prime \prime}$ & $3.38, \mathrm{~m}$ & $90.5, \mathrm{CH}$ & $\begin{array}{l}3.65, \mathrm{dd} \\
(9.5,8.8)\end{array}$ & $90.1, \mathrm{CH}$ \\
\hline $4^{\prime \prime}$ & $3.25, \mathrm{~m}$ & $69.0, \mathrm{CH}$ & $\begin{array}{l}3.58, \mathrm{dd} \\
(8.8)\end{array}$ & 70.0, $\mathrm{CH}$ \\
\hline $5^{\prime \prime}$ & $3.25, \mathrm{~m}$ & $81.4, \mathrm{CH}$ & $3.45, \mathrm{~m}$ & $82.8, \mathrm{CH}$ \\
\hline 6"a & $\begin{array}{l}3.72 \mathrm{dd} \\
(11.5,5.0)\end{array}$ & $61.1, \mathrm{CH}_{2}$ & $\begin{array}{l}3.90, \mathrm{dd} \\
(12.0,2.1)\end{array}$ & 63.0, $\mathrm{CH}_{2}$ \\
\hline 6"b & $3.42, \mathrm{~m}$ & & $\begin{array}{l}3.74, \mathrm{dd} \\
(12.0,5.4)\end{array}$ & \\
\hline $1^{\prime \prime \prime}$ & $\begin{array}{l}4.36, d \\
(8.0)\end{array}$ & 104.1, CH & $\begin{array}{l}4.62, d \\
(7.9)\end{array}$ & $105.4, \mathrm{CH}$ \\
\hline $2^{\prime \prime \prime}$ & $\begin{array}{l}3.10, \mathrm{t} \\
(8.0)\end{array}$ & $73.8, \mathrm{CH}$ & 3.31, ov. & 75.6, CH \\
\hline $3^{\prime \prime \prime}$ & $\begin{array}{l}3.18, \mathrm{t} \\
(8.0)\end{array}$ & $76.1, \mathrm{CH}$ & $\begin{array}{l}3.38, \mathrm{t} \\
(8.8)\end{array}$ & $78.8, \mathrm{CH}$ \\
\hline $4^{\prime \prime \prime}$ & $\begin{array}{l}3.06, \mathrm{t} \\
(8.0)\end{array}$ & $70.1, \mathrm{CH}$ & 3.31, ov. & 71.5, CH \\
\hline $5^{\prime \prime \prime}$ & $3.22, \mathrm{~m}$ & 76.9, $\mathrm{CH}$ & $3.36, \mathrm{~m}$ & $78.1, \mathrm{CH}$ \\
\hline $6^{\prime \prime \prime}$ & $3.42, \mathrm{~m}$ & $61.3, \mathrm{CH}_{2}$ & $\begin{array}{l}3.66, \mathrm{dd} \\
(12.1,5.5)\end{array}$ & 62.7, $\mathrm{CH}_{2}$ \\
\hline & $\begin{array}{l}3.69, \mathrm{dd} \\
(11.5,3.5)\end{array}$ & & & $\begin{array}{l}3.90 \text { (12.1, } \\
2.1)\end{array}$ \\
\hline $4^{\prime} \mathrm{CH}_{3}$ & $3.86, \mathrm{~s}$ & $55.5, \mathrm{CH}_{3}$ & $3.89, \mathrm{~s}$ & $56.2, \mathrm{CH}_{3}$ \\
\hline $5-\mathrm{OH}$ & $13.59, \mathrm{~s}$ & & & \\
\hline
\end{tabular}

range $=0.02-4.0 \mathrm{~min}$, $\mathrm{RT}$ wavelet range $=0.02-0.6 . \mathrm{MS} / \mathrm{MS}$ scans were paired using a $\mathrm{m} / \mathrm{z}$ tolerance of $0.02 \mathrm{Da}$ and a RT tolerance of $1.0 \mathrm{~min}$. The chromatogram was deisotoped using the isotopic peak grouper

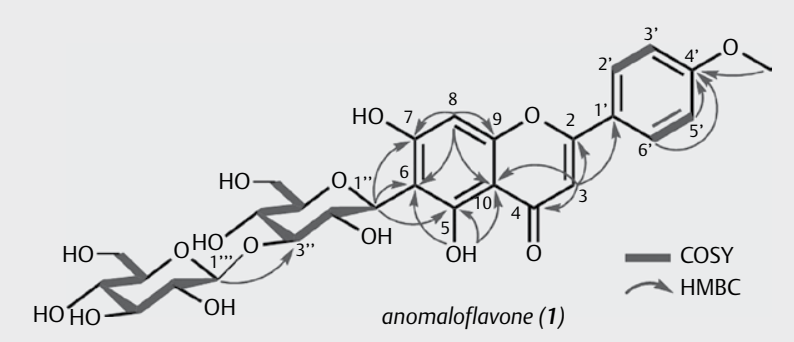

> Fig. 5 Key COSY and HMBC correlations of anomaloflavone (1).

algorithm with a $\mathrm{m} / \mathrm{z}$ tolerance of $0.02 \mathrm{Da}$ or $10 \mathrm{ppm}$ and a RT tolerance of $1.0 \mathrm{~min}$. The. $\mathrm{mgf}$ preclustered data file and the associated . csv feature quantification table (for RT, areas, and formula integrations) were further exported using the dedicated built-in options. A molecular network was finally created with MS-Cluster Off, a parent ion mass tolerance of $0.05 \mathrm{Da}$ and a fragment ion mass tolerance of 0.05 Da to generate consensus spectra. Consensus spectra containing less than one spectrum were discarded. Edges were filtered to have a minimal cosine score of 0.6 with at least six matched fragment peaks and further maintained if both nodes appeared in each other top 10 most similar nodes. Matches against the GNPS spectral libraries required a minimal cosine of 0.6 and at least six matched fragment peaks. The generated molecular networks were visualized using $\mathrm{Cy}$ toscape 3.5.1 [45].

\section{Extraction and purification of compounds}

Dried leaves of E. anomala $(3.0 \mathrm{~kg})$ were milled and extracted by maceration with $\mathrm{EtOH}(6 \times 10 \mathrm{~L}, 24 \mathrm{~h}$ each, room temperature, atmospheric pressure). The EtOH extract was concentrated in vacuo at $40^{\circ} \mathrm{C}$ to afford $494 \mathrm{~g}$ of dry residue. An aliquot of $200 \mathrm{~g}$ of this dry residue was dissolved in distillated water $(1000 \mathrm{~mL})$ and this solution was submitted to extraction with $n$-hexane $(400 \mathrm{~mL} \times 7)$ to afford a $n$-hexane fraction $(E A H)(109 \mathrm{~g})$. The aqueous phase was then alkalinized using $6 \mathrm{M} \mathrm{NH}_{4} \mathrm{OH}$ (until a pH ca. 12 was reached) prior to being re-extracted with methylene chloride $(300 \mathrm{~mL} \times 4)$ to afford $110 \mathrm{~g}$ of dry residue (subfraction EAD1) and finally with EtOAc $(300 \mathrm{~mL} \times 6)$ (subfraction EAE1, $879 \mathrm{mg})$. A relatively similar extraction process was repeated on another aliquot of the crude ethanolic extract $(160 \mathrm{~g})$, differing from the former by lacking the alkalinization step. In brief, this new aliquot of crude ethanolic extract was dissolved in distillated water $(1000 \mathrm{~mL})$ to be extracted with DCM $(400 \mathrm{~mL} \times 3)$ to afford a second DCM fraction (EAD2) $(112 \mathrm{~g})$. The aqueuous phase was subsequently reextracted with $\operatorname{EtOAc}(250 \mathrm{~mL} \times 5)(\mathrm{EAE} 2,2 \mathrm{~g})$ and at last with $n-\mathrm{BuOH}(150 \mathrm{~mL} \times 4)$ (EAB, $7.1 \mathrm{~g})$.

The dichloromethane subfraction EAD1 was fractionated by silica gel column chromatography using a gradient mobile phase consisting of a DCM/EtOAc solvent system (stepwise gradient 10:0 to 9:1) to afford 12 fractions EAD1A-EAD1L. Fraction EAD1C (11.5g) was selected for further purification by normal-phase silica gel column chromatography using an isocratic regime consisting of $n$ hexane/acetone $(6: 4)$ to afford subfractions EAD1C1-EAD1C5. Subfraction EAD1C2 $(1.2 \mathrm{~g})$ was selected for chromatography on Sephadex LH-20 to be isocratically eluted with a DCM/MeOH (2:1) mobile phase to afford compound $3(3.2 \mathrm{mg})$. Likewise, subfraction 
- Table $2{ }^{1} \mathrm{H}$ and ${ }^{13} \mathrm{C}$ NMR Data for Anomalovicenin (2) (DMSO- $d_{6}$ at 373 K, 500/125 MHz).

\begin{tabular}{|c|c|c|}
\hline & (2) ${ }^{a}$ & \\
\hline no. & $\delta_{\mathrm{H}}$, mult. $(\mathrm{In} \mathrm{Hz})$ & $\delta_{\mathrm{C}}$, type \\
\hline 2 & & 163.1, C \\
\hline 3 & $6.76, \mathrm{~s}$ & 102.7, CH \\
\hline 4 & & 181.9, C \\
\hline 5 & & 159.3, C \\
\hline 6 & & 109.1, C \\
\hline 7 & & 161.1, C \\
\hline 8 & & 105.1, C \\
\hline 9 & & 155.3, C \\
\hline 10 & & 103.0, C \\
\hline $1^{\prime}$ & & $123.0, \mathrm{C}$ \\
\hline $2^{\prime}$ & $8.06, \mathrm{~d}(8.3)$ & $128.2, \mathrm{CH}$ \\
\hline $3^{\prime}$ & $7.11, \mathrm{~d}(8.3)$ & $114.3, \mathrm{CH}$ \\
\hline $4^{\prime}$ & & 162.1, C \\
\hline $5^{\prime}$ & $7.11, \mathrm{~d}(8.3)$ & $114.3, \mathrm{CH}$ \\
\hline $6^{\prime}$ & $8.06, \mathrm{~d}(8.3)$ & $128.2, \mathrm{CH}$ \\
\hline Xyl-1" & $4.67, \mathrm{~d}(8.0)$ & $74.1, \mathrm{CH}$ \\
\hline Xyl-2" & $3.95, \mathrm{~m}$ & 70.6, CH \\
\hline Xyl-3"' & $3.24, \mathrm{t}(8.2)$ & 78.7, $\mathrm{CH}$ \\
\hline Xyl-4" & $3.50, \mathrm{~m}$ & $69.5, \mathrm{CH}$ \\
\hline Xyl-5"' & $\begin{array}{l}3.17, \mathrm{~d}(10.0) \\
3.86, \mathrm{dd}(10.0,4.7)\end{array}$ & $70.0, \mathrm{CH}_{2}$ \\
\hline Glc-1"'" & $4.95, \mathrm{~d}(8.0)$ & $74.2, \mathrm{CH}$ \\
\hline Glc-2"' & $3.71, \mathrm{~m}$ & $71.0, \mathrm{CH}$ \\
\hline Glc-3"'" & $3.43, \mathrm{t}(8.9)$ & $78.1, \mathrm{CH}$ \\
\hline Glc-4"'" & $3.51, \mathrm{~m}$ & $71.5, \mathrm{CH}$ \\
\hline Glc-5"' & $3.44, \mathrm{~m}$ & $81.2, \mathrm{CH}$ \\
\hline Glc-6"'" & $\begin{array}{l}3.66, \mathrm{~m} \\
3.74, \mathrm{dd}(11.5,3.5)\end{array}$ & $61.3, \mathrm{CH}_{2}$ \\
\hline $4^{\prime} \mathrm{CH}_{3}$ & $3.87, \mathrm{~s}$ & $55.2, \mathrm{CH}_{3}$ \\
\hline $5-\mathrm{OH}$ & $13.71, \mathrm{~s}$ & \\
\hline
\end{tabular}

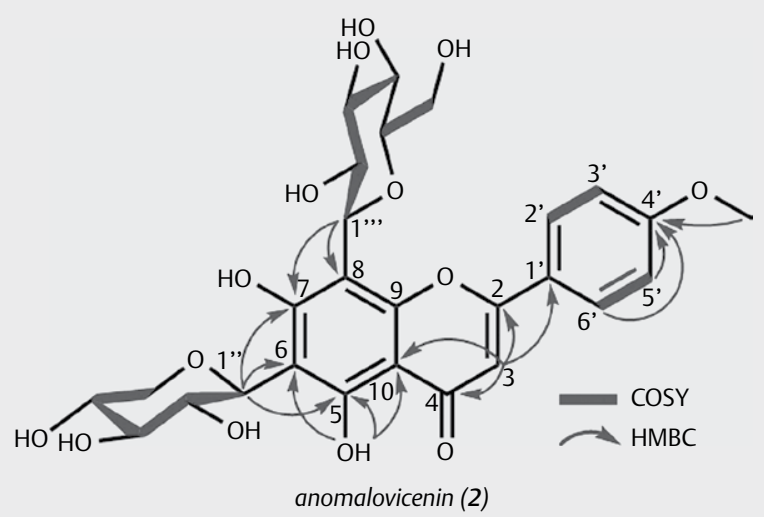

Fig. 6 Key COSY, HMBC, and NOESY correlations for anomalovice$\operatorname{nin}(2)$.
EAD1C5 (2.3 g) was selected for chromatography on Sephadex $\mathrm{LH}-20$ to be isocratically eluted with a DCM/MeOH (2:1) mobile phase to afford syringaresinol (13.4 mg). Fraction EAD1G (9 g) further fractionated by normal-phase silica gel column chromatography using an isocratic regime consisting of $n$-hexane/acetone (6:4) to afford subfractions EAD1G1-4. Subfraction EAD1G4 (1.7g) was subjected to column chromatography on Sephadex, and isocratically eluted with a $n$-hexane/acetone (6:4) mobile phase to afford lariciresinol (1.9 mg). Fraction EAD1l ( $2.9 \mathrm{~g})$ was selected for further purification by normal-phase silica gel column chromatography using an isocratic regime consisting of $n$-hexane/acetone (6:4) to afford subfractions EAD111-6. Subfraction EAD112 (1.5 g) was subsequently purified by chromatography on Sephadex LH-20 using an isocratic regime consisting of a $n$-hexane/EtOAc (7:3) mobile phase to afford tanarifuranonol $(1.1 \mathrm{mg})$.

The subfraction EAE1 $(879 \mathrm{mg}$ ) was separated by normal-phase silica gel column, eluted with a solvent system of DCM/MeOH (stepwise gradient, 99:1 to 9:1) to afford 12 fractions (EAE1A-EAE1L). The subfraction EAE1F $(250 \mathrm{mg})$ was subsequently fractionated by normal-phase silica gel column chromatography using an isocratic regime consisting of $n$-hexane/acetone (5:5) to afford subfractions EAE1F1-EAEF4. Among these, EAE1F4 $(120 \mathrm{mg})$ was finally chromatographed on Sephadex LH-20 using an isocratic DCM/MeOH (2:1) mobile phase to afford orcinol $(60 \mathrm{mg})$. The subfraction EAE1H $(200 \mathrm{mg}$ ) was selected for further purification by normal-phase silica gel column chromatography using an isocratic regime consisting of $n$-hexane/acetone (6:4) to afford subfractions EAE1H1EAEH3. Among these, EAE1H2 $(51 \mathrm{mg})$ was selected for further purification by normal-phase silica gel column chromatography using an isocratic regime consisting of $n$-hexane/acetone (7:3) and was fractionated by HPLC separation using a gradient system of ACN$\mathrm{H}_{2} \mathrm{O}$ with $0.1 \% \mathrm{HCOOH}(9: 1$ to $7: 3)$ to afford trematine $(61 \mathrm{mg})$ and isocytisoside ( $1.7 \mathrm{mg}$ ).

The subfraction EAE1] ( $87 \mathrm{mg}$ ) was selected for further purification by normal-phase silica gel column chromatography using an isocratic regime consisting of $n$-hexane/acetone (6:4) to afford subfractions EAE1J1-EAEJ5. Among these, EAE1J3 $(40 \mathrm{mg})$ was subsequently chromatographed on Sephadex $\mathrm{LH}-20$ using an isocratic $\mathrm{DCM} / \mathrm{MeOH}(2: 1)$ mobile phase to afford 4 (3 mg).

The subfraction $E A B(7.1 \mathrm{~g})$ was subjected to silica gel column chromatography using a EtOAc/MeOH (99:1 to 9:1) giving 11 fractions EAB1-11. Fractions EAB9 $(930 \mathrm{mg})$, EAB $10(890 \mathrm{mg})$, and EAB11 $(730 \mathrm{mg})$ were all fractionated by HPLC separation using a gradient system of $\mathrm{ACN}-\mathrm{H}_{2} \mathrm{O}$ with $0.1 \% \mathrm{HCOOH}$ (9:1 to $7: 3$ ) to respectively afford vitexine $(25.2 \mathrm{mg})$, and $\mathbf{1}(17.2 \mathrm{mg})$.

Anomaloflavone (1). Yellow amorphous solid; $[\alpha]_{D}^{25}-33.3$ (c0.031, in $\mathrm{MeOH}) ; \mathrm{UV}(\mathrm{MeOH}) \lambda_{\max }(\log \varepsilon) 349$ (4.31), 272 (4.17), 243 (4.15) $\mathrm{nm} ;{ }^{1} \mathrm{H}$ NMR $\left(500 \mathrm{MHz}, \mathrm{MeOH}-\mathrm{d}_{4}\right.$ and DMSO- $\left.\mathrm{d}_{6}\right)$ see $>$ Table $1,{ }^{13} \mathrm{C}$ $\operatorname{NMR}\left(125 \mathrm{MHz}, \mathrm{MeOH}-\mathrm{d}_{4}\right.$ and DMSO- $\left.\mathrm{d}_{6}\right)$ see $\gg$ Table 1 , HRESIMS m/z $609.1816[\mathrm{M}+\mathrm{H}]^{+}$(calcd. for $\left.\mathrm{C}_{28} \mathrm{H}_{33} \mathrm{O}_{15}, 609.1814\right)$. MS/MS spectrum was deposited in the GNPS spectral libraries under the identifier CCMSLIB00005788115.

Anomalovicenin (2). Yellow amorphous solid; $[\alpha]_{D} 25+22.7$ (c 0.044, in $\mathrm{MeOH})$; UV (MeOH) $\lambda_{\max }(\log \varepsilon) 333$ (4.29), 273 (4 .16), $227(4.12) \mathrm{nm} ;{ }^{1} \mathrm{H}$ NMR $\left(400 \mathrm{MHz}\right.$, DMSO- $\mathrm{d}_{6}$ at $\left.373 \mathrm{~K}\right)$ see $>$ Table 2, ${ }^{13} \mathrm{C}$ NMR $\left(125 \mathrm{MHz}\right.$, MeOH-d4 and DMSO- $\left.d_{6}\right)$ see > Table 2, HRESIMS m/z 579.1713 [M+H] ${ }^{+}$(calcd. for $\mathrm{C}_{27} \mathrm{H}_{31} \mathrm{O}_{14}, 579.17083$ ). 
MS/MS spectrum was deposited in the GNPS spectral libraries under the identifier CCMSLIB00005788116.

Anomaline (3). White amorphous solid. UV $(\mathrm{MeOH}) \lambda_{\max }(\log \varepsilon)$ 280 (3.71) nm; ${ }^{1} \mathrm{H}$ NMR ( $\left.400 \mathrm{MHz}, \mathrm{MeOH}-\mathrm{d}_{4}\right)$ see Table S1, ${ }^{13} \mathrm{C} \mathrm{NMR}$ $\left(100 \mathrm{MHz}, \mathrm{MeOH}-\mathrm{d}_{4}\right.$ ) see Table S1, HRESIMS m/z 183.1025 $[\mathrm{M}+\mathrm{H}]^{+}$(calcd. for $\left.\mathrm{C}_{10} \mathrm{H}_{15} \mathrm{O}_{3}, 183.1016\right)$. MS/MS spectrum was deposited in the GNPS spectral libraries under the identifier CCMSLIB00005788117.

Diorcinol (4). White amorphous solid. UV $(\mathrm{MeOH}) \lambda_{\max }(\log \varepsilon)$ 280 (3.71) nm; ${ }^{1} \mathrm{H}$ NMR ( $400 \mathrm{MHz}, \mathrm{MeOH}-\mathrm{d}_{4}$ ) see Table S2, ${ }^{13} \mathrm{C} \mathrm{NMR}$ $\left(100 \mathrm{MHz}, \mathrm{MeOH}-\mathrm{d}_{4}\right.$ ) see Table S2, HRESIMS m/z 261.1134 $[\mathrm{M}+\mathrm{H}]^{+}$(calcd. for $\left.\mathrm{C}_{15} \mathrm{H}_{17} \mathrm{O}_{4}, 261.1121\right)$. MS/MS spectrum was deposited in the GNPS spectral libraries under the identifier CCMSLIB00005788118.

\section{Antibacterial activity}

A broth microdilution method was used to determine the MIC values of the isolated compounds (1-2) against bacteria. The MIC values of the samples were determined using Staphylococcus aureus (ATCC 6538), Pseudomonas aeruginosa (ATCC 15442) and Mycobacterium smegmatis (CIP 7326). In brief, $100 \mu \mathrm{L}$ of the pure compounds $(1 \mathrm{mg} / \mathrm{mL})$ dissolved in DMSO were added to $100 \mu \mathrm{L}$ of bacterial culture in Mueller Hinton medium in triplicate and serially diluted twofold in 96 -well microtiter plates. The plates were incubated overnight at $37^{\circ} \mathrm{C}$, and the MIC value was determined as the lowest concentration inhibiting bacterial growth. To further discriminate a bactericidal effect from a bacteriostatic effect, $10 \mu \mathrm{L}$ of the bacterial suspension were inoculated onto a on Tryptic Soya Agar plate, and the bacterial growth was assessed after $24 \mathrm{~h}$ of incubation. Positive control drugs were vancomycin hydrochloride (Cayman Chem, purity $\geq 95 \%$ ) for Staphylococcus aureus, cetrimide (Sigma, purity $\geq 95 \%$ ) for Pseudomonas aeruginosa, and rifampicin (Sigma, purity $\geq 97 \%$ ) for Mycobacterium smegmatis.

\section{Cytotoxicity assessment}

Cytotoxicity of the compounds was investigated on the human cervical cancer cell line, SiHa, in a MTT assay. Briefly, cells $\left(5.10^{4} / \mathrm{mL}\right)$ were seeded in a 96 -well plate at $100 \mu \mathrm{l} /$ well and incubated at $37^{\circ} \mathrm{C}$ with $5 \% \mathrm{CO}_{2}$ for $24 \mathrm{~h}$. Two-fold serial dilutions of compounds (in same culture DMEM- $10 \%$ bovine serum) were added ( $100 \mu \mathrm{l} /$ well) to the adherent $\mathrm{SiHa}$ cells and further incubated for 3 days at $37^{\circ} \mathrm{C}$. MTT reagent $(0.5 \mathrm{mg} / \mathrm{mL}$ final concentration) was added to each well and $4 \mathrm{~h}$ later plate was washed twice with PBS (phosphate buffer saline). Formazan crystals were dissolved in $100 \mu \mathrm{l} /$ well DMSO and absorbance was measured at $570 \mathrm{~nm}$ and $630 \mathrm{~nm}$ using microplate reader (Bio-Rad 680). The results were expressed as the percentage of optical density (OD) values (\% of cell viability) relative to the optical density (OD) values from the control cells, without compounds (set to $100 \%$ viability). Positive control drug was orlistat (Cayman Chem, purity $\geq 98 \%$ ).

\section{Acknowledgments}

NMR analyses reported in this manuscript benefitted from the facilities of the PRISM research platform (Rennes, France) and Pr. Joël Boustie is gratefully acknowledged for having facilitated these analyses.

\section{Conflict of Interest}

The authors declare that they have no conflict of interest.

\section{References}

[1] Webster GL. Euphorbiaceae. In: Kubitzki K, Editor. Flowering Plants Eudicots. Heidelberg: Springer-Verlag; 2014: 51-216

[2] Burkill HM. The useful plants of west tropical Africa. Volume 2 : Families El. Royal Botanic Garden Kew 1994; 636

[3] Fox Ramos AE, Evanno L, Poupon E, Champy P, Beniddir MA. Natural products targeting strategies involving molecular networking: Different manners, one goal. Nat Prod Rep 2019; 36: 960-980

[4] Fox Ramos AE, Pavesi C, Litaudon M, Dumontet V, Poupon E, Champy $P$ et al. CANPA: computer-assisted natural products anticipation. Anal Chem 2019; 91: 11247-11252

[5] Allen F, Greiner R, Wishart D. Competitive fragmentation modeling of ESI-MS/MS spectra for putative metabolite identification. Metabolomics 2015; 11: 98-110

[6] Beauxis Y, Genta-Jouve G. MetWork: a web server for natural products anticipation. Bioinformatics 2019; 35: 1795-1796

[7] Turpin V, Beniddir MA, Genta-Jouve G, Skiredj A, Gallard J-F, Leblanc K et al. In silico anticipation of metabolic pathways extended to organic chemistry reactions: a case study with caffeine alkaline hydrolysis and the origin of camellimidazoles. Chem Eur J 2020; 26: 12936-12940

[8] Nothias L-F, Petras D, Schmid R, Dührkop K, Rainer J, Sarvepalli A et al. Feature-based molecular networking in the GNPS analysis environment. Nat Methods 2020; 17: 905-908

[9] Wang M, Carver J], Phelan VV, Sanchez LM, Garg N, Peng Y et al. Sharing and community curation of mass spectrometry data with Global Natural Products Social Molecular Networking. Nat Biotechnol 2016; 34: 828-837

[10] Rizk A-FM. The chemical constituents and economic plants of the Euphorbiaceae. Bot J Lin Soc 1987; 94: 293-326

[11] Kuster RM, Mors WB, Wagner H. Orcinol glucosides from Phyllanthus klotzschianus. Fitoterapia. 1996; 67: 283-284

[12] Cuyckens F, Claeys M. Mass spectrometry in the structural analysis of flavonoids. J Mass Spectrom 2004; 39: 1-15

[13] Markham KR, Chari VM. Carbon-13 NMR Spectroscopy of Flavonoids. In: Harborne JB, Mabry TJ, Editors. The Flavonoids. Boston, MA: Springer US; 1982: 50

[14] Pluskal T, Castillo S, Villar-Briones A, Orešič M. MZmine 2: modular framework for processing, visualizing, and analyzing mass spectrometry-based molecular profile data. BMC bioinformatics 2010; 11: 1-11

[15] Waridel P, Wolfender J-L, Ndjoko K, Hobby KR, Major HJ, Hostettmann $K$. Evaluation of quadrupole time-of-flight tandem mass spectrometry and ion-trap multiple-stage mass spectrometry for the differentiation of C-glycosidic flavonoid isomers. J Chromatogr A 2001; 926: 29-41

[16] Pereira CAM, Yariwake JH, McCullagh M. Distinction of the C-glycosylflavone isomer pairs orientin/isoorientin and vitexin/isovitexin using HPLC-MS exact mass measurement and in-source CID. Phytochem Anal 2005; 16: 295-301

[17] Li QM, Claeys M. Characterization and differentiation of diglycosyl flavonoids by positive ion fast atom bombardment and tandem mass spectrometry. Biol Mass Spectrom 1994; 23: 406-416

[18] Colombo R, Yariwake JH, McCullagh M. Study of C- and O-glycosylflavones in sugarcane extracts using liquid chromatography: exact mass measurement mass spectrometry. J Braz Chem Soc 2008; 19: 483-490 
[19] Kite GC, Porter EA, Denison FC, Grayer RJ, Veitch NC, Butler I et al. Data-directed scan sequence for the general assignment of C-glycosylflavone $\mathrm{O}$-glycosides in plant extracts by liquid chromatography-ion trap mass spectrometry. J Chromatogr A 2006; 1104: 123-131

[20] Becchi M, Fraisse D. Fast atom bombardment and fast atom bombardment collision-activated dissociation/mass-analysed ion kinetic energy analysis of C-glycosidic flavonoids. Biomed Environ Mass Spectrom 1989; 18: 122-130

[21] Qimin L, van den Heuvel H, Delorenzo O, Corthout J, Pieters LAC, Vlietinck AJ et al. Mass spectral characterization of C-glycosidic flavonoids isolated from a medicinal plant (Passiflora incarnata). J Chromatogr B 1991; 562: 435-446

[22] Wirasutisna KR, Gleye J, Moulis C, Stanislas E, Moretti C. Flavone C-Glycosides of Almeidea guyanensis. Phytochemistry 1986; 25 : 558-559

[23] DNP http://dnp.chemnetbase.com/ 2021;

[24] Nawwar MAM, Buddrus ], Bauer H. Dimeric phenolic constituents from the roots of Tamarix nilotica. Phytochemistry 1982; 21: 1755-1758

[25] Fonseca SF, de Paiva Campello J, Barata LES, Rúveda EA. 13C NMR spectral analysis of lignans from Araucaria angustifolia. Phytochemistry 1978; 17: 499-502

[26] Phommart S, Sutthivaiyakit P, Chimnoi N, Ruchirawat S, Sutthivaiyakit S. Constituents of the Leaves of Macaranga tanarius. J Nat Prod 2005; 68: 927-930

[27] Choo CY, Sulong NY, Man F, Wong TW. Vitexin and isovitexin from the leaves of Ficus deltoidea with in-vivo $\alpha$-glucosidase inhibition. J Ethnopharmacol 2012; 142: 776-781

[28] Oelrichs P, Marshall JTB, Williams DH. 7-O- $\beta$-D-glucosyl-8-C- $\beta$-Dglucosyl-4'-O-methylapigenin. A new flavone from Trema aspera. J Chem Soc C 1968; 941-947

[29] Marston A, Hostettmann K, Jacot-Guillarmod A. Contribution à la phytochimie du genre Gentiana, XIX. Identification de nouveaux C-glucosides flavoniques dans Gentiana pyrenaica L. Helv Chim Acta 1976; 59: 2596-2600

[30] Lin M-T, Chen L-C, Chen C-K, Chen Liu KCS, Lee S-S. Chemical Constituents from Drypetes littoralis. J Nat Prod 2001; 64: 707-709

[31] Agrawal PK. Carbon-13 NMR of flavonoids. London: Elsevier; 1989

[32] Wawer I, Zielinska A. 13C CP/MAS NMR studies of flavonoids. Magn Reson Chem 2001; 39: 374-380
[33] Xu K-J, Xu X-M, Deng W-L, Zhang L, Wang M-K, Ding L-S. Three new flavone $C$-glycosides from the aerial parts of Paraquilegia microphylla. J Asian Nat Prod Res 2011; 13: 409-416

[34] Aquino R, Morelli S, Lauro MR, Abdo S, Saija A, Tomaino A. Phenolic Constituents and Antioxidant Activity of an Extract of Anthurium versicolor Leaves. J Nat Prod 2001; 64: 1019-1023

[35] Markham KR, Whitehouse LA. Unique flavonoid glycosides from the new zealand white pine, Dacrycarpus dacrydioides. Phytochemistry 1984; 23: 1931-1936

[36] Cheng Y, Schneider B, Oberthür C, Graf H, Adler S, Hamburger M. Flavone C-glycosides from Isatis tinctoria leaves. Heterocycles 2005; 65: $1655-1661$

[37] Lu Y, Yeap Foo L. Flavonoid and phenolic glycosides from Salvia officinalis. Phytochemistry 2000; 55: 263-267

[38] Xie C, Veitch NC, Houghton PJ, Simmonds MSJ. Flavone C-Glycosides from Viola yedoensis Makino. Chem Pharm Bull 2003; 51: 1204-1207

[39] Zhou G, Yan R, Wang X, Li S, Lin J, Liu J et al. The overlooked rotational isomerism of C-glycosyl flavonoids. Phytochemistry Reviews 2019; 18 : 443-461

[40] Daglia M. Polyphenols as antimicrobial agents. Curr Opin Biotechnol 2012; 23: 174-181

[41] Barbieri R, Coppo E, Marchese A, Daglia M, Sobarzo-Sánchez E, Nabavi SF et al. Phytochemicals for human disease: An update on plantderived compounds antibacterial activity. Microbiol Res 2017; 196: 44-68

[42] Dwivedi P, Bendiak B, Clowers BH, Hill HH. Rapid resolution of carbohydrate isomers by electrospray ionization ambient pressure ion mobility spectrometry-time-of-flight mass spectrometry (ESI-APIMSTOFMS). J Am Soc Mass Spectr 2007; 18: 1163-1175

[43] Chambers MC, Maclean B, Burke R, Amodei D, Ruderman DL, Neumann $S$ et al. A cross-platform toolkit for mass spectrometry and proteomics. Nat Biotechnol 2012; 30: 918-920

[44] Myers OD, Sumner SJ, Li S, Barnes S, Du X. One step forward for reducing false positive and false negative compound identifications from mass spectrometry metabolomics data: new algorithms for constructing extracted ion chromatograms and detecting chromatographic peaks. Anal Chem 2017; 89: 8696-8703

[45] Shannon P, Markiel A, Ozier O, Baliga NS, Wang JT, Ramage D et al. Cytoscape: A software environment for integrated models of biomolecular interaction networks. Genome Res 2003; 13: 2498-2504 